\title{
Vancomycin-conjugated polydopamine-coated magnetic nanoparticles for molecular diagnostics of Gram-positive bacteria in whole blood
}

\author{
Abdurhaman Teyib Abafogi \\ Sungkyunkwan University (SKKU) \\ Tepeng Wu \\ KingoBio Inc \\ Daekyu Lee \\ Sungkyunkwan University (SKKU) \\ Jinyeop Lee \\ Sungkyunkwan University (SKKU) \\ Gyoujin Cho \\ Sungkyunkwan University (SKKU) \\ Luke P. Lee \\ Sungkyunkwan University (SKKU) \\ Sungsu Park ( $\nabla$ nanopark@skku.edu ) \\ Sungkyunkwan University (SKKU)
}

\section{Research Article}

Keywords: Sepsis, Immunomagnetic separation, Preconcentration, Polydopamine, Molecular diagnostics, Aggregation

Posted Date: March 2nd, 2022

DOI: https://doi.org/10.21203/rs.3.rs-1397720/v1

License: (c) (1) This work is licensed under a Creative Commons Attribution 4.0 International License. Read Full License 


\section{Abstract}

Sepsis is caused mainly by infection in the blood with a broad range of bacterial species. It can be diagnosed by molecular diagnostics once compounds in the blood that interfere with molecular diagnostics are removed. However, this removal relies on ultracentrifugation. Immunomagnetic separation (IMS), which typically uses antibody-conjugated silica-coated magnetic nanoparticles (Ab$\mathrm{SiO}_{2}$-MNPs), has been widely applied to isolate specific pathogens in various types of samples, such as food and environmental samples. However, its direct use in blood samples containing bacteria is limited due to the aggregation of $\mathrm{SiO}_{2}$-MNPs in the blood and inability to isolate multiple species of bacteria causing sepsis.

Results: In this study, we report the synthesis of vancomycin-conjugated polydopamine-coated (van-PDAMNPs) enabling preconcentration of multiple bacterial species from blood without aggregation. The presence of PDA and van on MNPs was verified using transmission electron microscopy, X-ray photoelectron spectroscopy and energy disruptive spectroscopy. Unlike van-SiO ${ }_{2}-\mathrm{MNPs}$, van-PDA-MNPs did not aggregate in the blood. Van-PDA-MNPs were able to preconcentrate several species of Grampositive bacteria in the blood, lowering the limit of detection (LOD) to 10 colony forming units $/ \mathrm{mL}$ by polymerase chain reaction (PCR) and quantitative PCR. This is 10 times more sensitive than the LOD obtained by PCR and qPCR with the use of van-SiO ${ }_{2}-\mathrm{MNPs}$.

Conclusion: These results suggest that PDA-MNPs do not aggregate in blood and can be conjugated with receptors, thereby improving the sensitivity of molecular diagnostics for bacteria in blood samples.

\section{Background}

Sepsis is a life-threatening immune response to bloodstream bacterial infections [1, 2]. In 2017, about 48.9 million people were diagnosed with sepsis, while about 11 million worldwide died due to sepsis [2]. Unless it is detected early and timely interventions are applied, sepsis mortality increases up to $10 \%$ per hour [3]. Since the standard diagnostic method of a blood culture takes 24-48 $\mathrm{h}$ for detection [4], broadspectrum antibiotics must be used to treat patients without identification of the pathogens [3]. This reduces the effectiveness of treatment and increases the likelihood of antibiotic resistance [3]. Molecular diagnostics such as polymerase chain reaction (PCR) reduce detection times to $2 \mathrm{~h}$ [5]. However, endogenous inhibitory compounds such as heme and leukocyte DNA as well as anticoagulants such as EDTA and heparin [6] negatively affect PCR sensitivity [7]. Therefore, these inhibitory compounds should be removed from the sample prior to PCR [7].

Various techniques have been developed to isolate pathogens from samples, including filtration [8], centrifugation and sedimentation [9], inertial separation [10] and immunomagnetic separation (IMS) [11]. Among them, IMS is the most sensitive because it uses a target-specific antibody [12] conjugated to superparamagnetic silica-coated magnetic nanoparticles $\left(\mathrm{SiO}_{2}\right.$-MNPs) to capture a target pathogen through antigen-antibody interaction. However, when the silica surface is exposed to air or water, an oxide 
layer is formed on the surface of the silica tetrahedral crystals (silanol groups) [13]. Then, reactive oxygen species and reactive moieties of the silanol group interact with cell membranes [14], causing non-specific adsorption of blood cells and platelets. This adsorption causes aggregation of $\mathrm{SiO}_{2}-\mathrm{MNPs}$ and promotes transfer of residual inhibitory compounds to the DNA extraction step. These compounds then inhibit PCR amplification [7, 15]. Therefore, to improve the sensitivity of PCR for detection of sepsis, effort should be focused on the development of a surface coating method of MNPs that can reduce non-specific adsorption of blood cells and platelets.

Polydopamine (PDA) can prevent the non-specific binding of blood cells and platelets to micro/nanoparticles due to their strong hydrophilicity $[16,17]$. It is a highly adaptable polymer that can be used to coat a variety of materials in a single step through the oxidative self-polymerization of dopamine $[18,19]$. Because of its reactivity with amine and thiol functional groups, it can also be used to immobilize biomolecules to surfaces [18, 20,21]. For example, a PDA coating has been used to immobilize antimicrobial imidazolium-based ionic liquid to MNPs for the removal of bacteria from blood [17]. Similarly, PDA has been used to coat MNPs for the functionalization of probe oligonucleotides [22]. However, PDA-MNPs have not been used to enrich bacteria in blood to improve the sensitivity of molecular diagnostics.

To isolate a broad range of bacterial species, antibiotics can be conjugated to MNPs instead of speciesspecific antibodies $[23,24]$. Among antibiotics, van has been conjugated to MNPs to isolate Grampositive bacteria [24]. Van is a bacteriostatic antibiotic that inhibits bacterial cell wall synthesis by binding to the D-alanyl-D-alanyl terminus of the peptidoglycan layer of Gram-positive bacteria through hydrogen bonding $[25,26]$. Therefore, it has great potential for use in the separation of Gram-positive bacteria $[23,24]$. For example, van-MNPs were used to separate Gram-positive bacteria such as Staphylococcus aureus from whole blood and improved the sensitivity of quantitative PCR (qPCR) to about 5 colony forming units (CFU) per $1 \mathrm{~mL}$ of blood. However, the method still required the removal of blood cells using centrifugation due to their fouling with blood cells [24].

In this study, we report the synthesis of PDA-MNPs conjugated with van (van-PDA-MNPs) enabling the preconcentration of multiple bacterial species from blood without aggregation. The presence of PDA and van in the MNPs was verified using transmission electron microscopy (TEM), energy dispersive spectroscopy (EDS) mapping, zeta-potential measurement, and X-ray photoelectron spectroscopy (XPS) analysis. The advantages of van-PDA-MNPs were demonstrated by comparing the aggregation and bacterial preconcentration of van-PDA-MNPs and van-SiO ${ }_{2}$-MNPs in whole blood samples (Fig. 1). The feasibility of van-PDA-MNPs for molecular detection of Gram-positive bacteria in blood was tested with whole blood samples spiked with multiple species of Gram-positive bacteria and methicillin-resistant $S$. aureus (MRSA). Van-PDA-MNPs can preconcentrate these microorganisms up to 100-fold in the blood within 30 minutes, lowering the limit of detection (LOD) to $10 \mathrm{CFU} / \mathrm{mL}$ by PCR and qPCR.

\section{Results And Discussion}




\section{Characterization of van-PDA-MNPs}

For the synthesis of van-PDA-MNPs, freshly prepared MNPs were first coated with PDA and van was then grafted onto PDA-MNPs through the reaction of the primary amino group of van with the phenyl ring of PDA [27]. $\mathrm{SiO}_{2}$-MNPs were similarly conjugated (Supplementary Fig. 1). TEM images showed that vanPDA-MNPs had a dark core covered with a transparent layer (Fig. 3a). The transparent layer was not observed in van-SiO2-MNPs (Supplementary Fig. 2a). The dark core and transparent layer indicate the presence of iron oxide and PDA. The diameter of the dark core and the thickness of the PDA layer were $97.7 \pm 6.8 \mathrm{~nm}$ and $11.9 \pm 1 \mathrm{~nm}(\mathrm{n}=5)$.

XPS analyses showed that van-PDA-MNPs were coated with PDA and grafted with van (Fig. 3 b-d). MNPs were composed of Fe, $\mathrm{O}$ and $\mathrm{C}$ (Fig. 3b). The presence of PDA on the MNPs was confirmed by the three peaks of $\mathrm{O}, \mathrm{N}$ and $\mathrm{C}$, which are the elements of PDA (Fig. 3c). In van-PDA-MNPs, the characteristic peak of $\mathrm{Cl} 2 \mathrm{p}$ for van was observed (Fig. 3d), indicating the grafting of the amine group of van onto the carbon ring of PDA [27]. However, the Fe peak disappeared in PDA-MNPs because PDA coating thicker than 10 $\mathrm{nm}$ blocked X-ray penetration into the MNPs [28].

The alteration in the surface charge of MNPs by PDA coating and van conjugation was analysed by measuring the zeta potential of each type of MNP. The surface charges of MNPs, PDA-MNPs and vanPDA-MNPs were $-22.5 \pm 1.6,-13.1 \pm 0.7$ and $-7.9 \pm 0.7 \mathrm{mV}$, respectively, indicating that the negative charge of MNPs was reduced by the PDA coating and van conjugation (Fig. 3e). Coating of MNPs with $\mathrm{SiO}_{2}$ and conjugation of $\mathrm{SiO}_{2}$ with van also caused a reduction in the negative charge of MNPs (Supplementary Fig. 3). The results suggests that the relatively neutrally charged molecules such as $\mathrm{PDA}, \mathrm{SiO}_{2}$ and van compared to iron oxide nanoparticles can reduce the negative charge on the surface of MNPs when they are present on the surface.

The EDS mapping results showed a map of the elements (Fe, O, C and N) in each type of MNPs (Fig. $\mathbf{3 f}$ and Supplementary Fig. $\mathbf{2 b}$ ), confirming the results obtained by the TEM images and XPS analyses. EDS mapping could not accurately reflect the presence of chlorine due to its low amount (about $1.5 \%$ ) in van compared to the other elements (Table 1). Taken together, it is suggested that the MNPs were successfully coated with PDA and conjugated with van.

\section{Particle size distribution in PBS and blood}

To test whether PDA coating can reduce the aggregation of MNPs in blood, the particle size of van- $\mathrm{SiO}_{2}{ }^{-}$ MNPs and van-PDA-MNPs in PBS and blood was measured using Zetasizer Nano ZS (Malvern Instruments, Malvern, UK). Van-SiO ${ }_{2}$-MNPs did not aggregate in PBS, but severely aggregated in blood (Fig. 4a). This is supported by the size distribution of van-SiO $\mathrm{S}_{2}-\mathrm{MNPs}$ in PBS and blood showing a single peak and three peaks, respectively. In contrast, van-PDA-MNPs did not aggregate in either PBS or blood

(Fig. 4b), which is supported by the single peak in their size distribution. The aggregation of van- $\mathrm{SiO}_{2}{ }^{-}$ MNPs could be due to the binding of blood cells to their surface. The silica oxide surface often generates 
a reactive oxygen species and interacts with biological membranes [14], promoting the non-specific adsorption of blood cells to the MNPs and the aggregation. In contrast, the PDA surface prevents blood cells and platelets from binding to the surface of MNPs due to their strong hydrophilicity [16]. Our results suggest that the aggregation of MNPs in the blood could be prevented by the PDA coating.

\section{Preconcentration of different species of bacteria with van-PDA-MNPs}

Van-PDA-MNPs can bind to different strains (S. aureus, MRSA and Bacillus cereus), which was verified by scanning electron microscopy (SEM) (Fig. 5a). It was previously reported that van nanoparticles could capture Gram-positive bacteria including MRSA $[24,29,30]$. This is possible because van is a broadspectrum antibiotic that can target the peptidoglycan layer of various species of Gram-positive bacteria $[25,26]$.

The capturing efficiencies of all the tested strains in PBS by van-SiO${ }_{2}-\mathrm{MNPs}$ and van-PDA-MNPs and vanPDA were about 70 and $90 \%$. There is a significant difference $(P<0.001)$ in the capture efficiencies between the two types of MNPs (Fig. 5b). This leads to a difference in bacterial preconcentration capability between MNP types (Fig. 5c). Zhao et al. [31] reported that PDA coating increased surface area and binding sites with amino and hydroxyl groups for receptors. Therefore, the PDA coating may increase the amount of van on the surface of PDA-MNPs. As a result, the bacteria capturing efficiency increased.

The capturing efficiency and preconcentration capability of van-PDA-MNPs in blood were also greater than those of van-SiO ${ }_{2}$-MNPs (Fig. 5d, e). This might be due to the better compatibility of PDA coating with blood, reduced interaction and adhesion to blood cells and platelets [16]. As a result, it can easily capture the target bacteria without being blocked by blood cells. These results suggest that PDA coating eliminates the non-specific adsorption of blood cells onto MNPs and prevents formation of aggregates. To the best of our knowledge, this is the first time that van-PDA-MNPs are used to preconcentrate bacteria from whole blood.

\section{Improved molecular diagnostics for bacteria in blood through preconcentration by van-PDA-MNPs}

qPCR was used to test whether preconcentration of bacteria by van-PDA-MNPs can improve the sensitivity of molecular diagnostics for bacteria in the blood. DNA extracted from $S$. aureus in the blood by a genomic DNA extraction kit was used as a control without preconcentration by any type of MNP. Without the preconcentration, as low as $10^{4} \mathrm{CFU} / \mathrm{mL}$ was detectable (Fig. 6a). With the use of either van$\mathrm{SiO}_{2}$-MNPs or van-PDA-MNPs, as low as $10^{2}$ and $10 \mathrm{CFU} / \mathrm{mL}$ were detectable, respectively. A similar result was observed in PCR (Fig. 6b-d). The results showed that the bacterial concentration by van- $\mathrm{SiO}_{2}-$ MNPs was not as good as that by van-PDA-MNPs for molecular diagnostics in the blood. This can be explained by Table 2, which shows that absorbance at $260 / 280 \mathrm{~nm}$ of purified DNA of bacteria preconcentrated by the former and latter beads was lower than and higher than 1.8 , respectively. The absorbance ratio at $260 / 280 \mathrm{~nm}$ lower than 1.8 indicates protein contamination in the purified DNA. The contamination could occur due to the non-specific adsorption of blood cells to van-SiO${ }_{2}-\mathrm{MNPs}$, lowering 
extracted DNA concentration and PCR amplification. On the other hand, the absorbance ratio at 260/280 $\mathrm{nm}$ for DNA obtained after preconcentration with van-PDA-MNPs and DNA extraction shows that the DNA is of high quality. Higher quality DNA was achieved as the non-specific adsorption of blood cells to the MNPs was prevented by the PDA coating. As a result, as low as $10 \mathrm{CFU} / \mathrm{mL}$ of $S$. aureus was detectable in the blood. In PBS, there was almost no difference in the sensitivity of qPCR for the pathogen between van-SiO2-MNPs and van-PDA-MNPs (Supplementary Fig. 4). The results suggest that the use of van-PDAMNP eliminated the non-specific adsorption of blood cells and the formation of aggregates in the blood, which resulted in successful removal of the PCR inhibitory compounds and improved LOD. As previously reported [23,32], van and lectin conjugated with MNPs were used to magnetically separate bacteria from blood. As the conventionally used MNPs interact with blood cells and form aggregates, they have included an extra step for treating whole blood to remove the blood cells through natural sedimentation [23] or centrifugation after they have lysed red blood cells [32]. Because of the ability of the PDA coating to prevent non-specific adsorption of blood cells and aggregation, van-PDA-MNPs can be used to capture and preconcentrate target bacteria from whole blood without the need for additional pretreatment steps.

\section{Multiplex preconcentration of $S$. aureus, MRSA and B. cereus in blood with van-PDA-MNPs for molecular diagnostics}

qPCR and PCR were used to verify the performance of simultaneous preconcentration of several bacterial strains ( $S$. aureus, MRSA and B. cereus) in the blood with van-PDA-MNPs. All strains were detectable at as low as $10 \mathrm{CFU} / \mathrm{mL}$ by qPCR and PCR (Fig. 7). This demonstrates that the use of van-PDA-MNPs prevented non-specific adsorption of blood cells and formation of aggregates. Thus, van-PDA-MNPs can eliminate cumbersome pretreatment steps such as separation of blood cells prior to the preconcentration of bacteria. As a result, the time required for preconcentration of pathogens can be reduced to $30 \mathrm{~min}$.

\section{Conclusion}

In this study, we synthesized MNPs coated with PDA and conjugated with van to separate multiple species of bacteria without aggregation of the MNPs. The LOD of molecular diagnostics for bacteria in blood samples through IMS with van-PDA-MNPs was $10 \mathrm{CFU} / \mathrm{mL}$, which is close to culture-free detection. Since IMS with van-PDA-MNPs does not require prior sample pretreatment steps such as separation of blood cells and dilution, bacterial preconcentration takes only $30 \mathrm{~min}$. Van-PDA-MNPs can be used to preconcentrate only Gram-positive bacteria. However, their combined use of PDA-MNPs conjugated with polymyxin B, which targets Gram-negative bacteria, could enable simultaneous preconcentration of Gram-positive and Gram-negative bacteria in blood samples. On the other hand, antibodies conjugated to PDA-MNPs can be used to enrich and diagnose different viruses or isolate circulating tumour cells.

\section{Materials And Methods}

\section{Reagents}


Ferric chloride hexahydrate, sodium acetate, ethylene glycol, 25\% ammonia solution, 99\% tetraethoxysilane (TEOS), (3-aminopropyl)triethoxysilane (APTES), 25\% glutaraldehyde solution, sodium tetraborate, dopamine hydrochloride, vancomycin hydrochloride, oxacillin sodium salt and $99 \%$ osmium tetroxide $\left(\mathrm{OsO}_{4}\right)$ were purchased from Sigma-Aldrich (St. Louis, MO, USA). Phosphate-buffered saline (PBS, pH 7.4) was purchased from Gibco (Grand Island, NY, USA).

\section{Bacterial culture}

S. aureus (25923) and B. cereus (21722) were obtained from American Type Culture Collection (ATCC, Manassas, VA, USA). MRSA (3107) was obtained from Culture Collection of Antimicrobial Resistance Microbes (Seoul, Korea). A single colony of either $S$. aureus or B. cereus was transferred from the agar plate to $5 \mathrm{~mL}$ of Luria-Bertani (LB) broth (Becton, Dickinson and Company, Franklin Lakes, NJ, USA). LB broth supplemented with $6 \mu \mathrm{g} / \mathrm{mL}$ of oxacillin sodium salt was used to grow MRSA. Then, the culture was incubated overnight at $37^{\circ} \mathrm{C}$ and $200 \mathrm{rpm}$. Fifty microliters of the overnight culture were transferred to a fresh $5 \mathrm{ml}$ LB broth. Finally, it was incubated under the same conditions until the optical density (OD) measurement at $600 \mathrm{~nm}$ reached 1 .

\section{Preparation of MNPs}

Ferric chloride hexahydrate $(0.54 \mathrm{~g})$ and sodium acetate $(0.5 \mathrm{~g})$ were dissolved in $20 \mathrm{~mL}$ ethylene glycol with continuous stirring [33]. The solution was then transferred to a 100-mL Teflon-lined hydrothermal autoclave and kept at $200^{\circ} \mathrm{C}$ for $10 \mathrm{~h}$. The autoclave was then kept at room temperature (RT) until it cooled down. The obtained MNPs were washed three times with $40 \mathrm{~mL}$ of deionized water and dried overnight. $100 \mathrm{mg}$ of the MNPs were dispersed in $40 \mathrm{~mL}$ of $\mathrm{HCL}(1 \mathrm{M})$ and incubated at RT for $1 \mathrm{~h}$ under constant mixing. The MNPs were then collected using a permanent magnet and washed three times with PBS.

\section{Coating of MNPs with $\mathrm{SiO}_{2}$ and conjugation with van}

$0.5 \mathrm{~mL}$ of $25 \%$ ammonia solution and $0.2 \mathrm{~mL}$ of TEOS were added into $10 \mathrm{~mL}$ of deionized water containing $20 \mathrm{mg}$ of MNPs in a sequential manner. The mixture was incubated for $24 \mathrm{~h}$ at RT [34]. MNPs were then washed three times with PBS ( $\mathrm{pH}$ 7.4) and collected by using a permanent magnet. MNPs were then functionalized with an amine group by transferring $2 \mathrm{mg}$ of $\mathrm{SiO}_{2}-\mathrm{MNPs}$ to a $1.5-\mathrm{mL}$ tube containing $1 \mathrm{~mL}$ of $5 \%$ (3-aminopropyl) triethoxysilane $(\mathrm{pH} 4)$ and incubating at RT for $3 \mathrm{~h}$. MNPs functionalized with the amine group were then mixed with $2.5 \%$ glutaraldehyde solution and incubated at RT for 30 min. The MNPs were then washed with $1 \mathrm{~mL}$ of $0.01 \mathrm{M}$ borate buffer. Finally, $2 \mathrm{mg}$ of van was added, and the mixture was incubated overnight. After washing three times with PBS, the MNPs were dispersed in $1 \mathrm{~mL}$ PBS.

\section{Coating of MNPs with PDA and conjugation with van}


Fifty milligrams of MNPs were added to $25 \mathrm{~mL}$ of dopamine hydrochloride solution $(2 \mathrm{mg} / \mathrm{mL}, \mathrm{pH} 8.5)$ and incubated for $3 \mathrm{~h}$ under continuous stirring at RT [35]. PDA-MNPs were then separated by using a permanent magnet and washed three consecutive times with PBS. $25 \mathrm{~mL}$ of vancomycin hydrochloride solution ( $2 \mathrm{mg} / \mathrm{mL}, \mathrm{pH} 7.4$ ) was added to the PDA-MNPs and incubated at RT for $3 \mathrm{~h}$ (Fig. 2). Finally, MNPs were separated using a permanent magnet, washed three consecutive times with PBS and suspended in $25 \mathrm{~mL}$ PBS [34].

\section{Transmission electron microscopy (TEM) imaging}

Two milligrams of the MNPs, PDA-MNPs and van-PDA-MNPs were washed three times with $1 \mathrm{~mL}$ DI water and suspended in $1 \mathrm{~mL}$ DI water. Ten microliters of the particles were then dropped onto a $300-$ mesh copper grid (CF-2/1-3CU-50) from Electron Microscopy Sciences (Hatfield, PA, USA) and dried at $70^{\circ} \mathrm{C}$ for $2 \mathrm{~h}$. Finally, morphology and elemental mapping of the particles were obtained at an accelerating voltage of $200 \mathrm{kv}$ by using JEM-2100F TEM (JEOL Ltd., Tokyo, Japan) and EDS attached to the TEM machine.

\section{XPS analysis}

Dried MNPs were placed on a glass slide and the XPS spectra of the samples were obtained by using ESCALAB250 XPS analyser (ThermoFisher Scientific, Waltham, MA, USA).

\section{Zeta potential measurement}

Zeta potential measurements were performed by suspending $0.2 \mathrm{mg}$ particles in $1 \mathrm{~mL}$ of DI water and analysing it with Zetasizer Nano ZS.

\section{Particle size distribution in PBS and blood}

Two hundred microliters of van-SiO ${ }_{2}-M N P s$ or van-PDA-MNPs were added to $1 \mathrm{~mL}$ PBS or blood and incubated at $37^{\circ} \mathrm{C}$ for $30 \mathrm{~min}$. The MNPs were separated by using a magnetic separation rack (MagListo $^{\mathrm{TM}}$, Bioneer, Daejeon, Korea). MNPs were then washed three times with $1 \mathrm{~mL}$ PBS. Finally, they were suspended in $1 \mathrm{~mL}$ PBS and the size distribution of MNPs was analysed using Zetasizer.

\section{Scanning electron microscopy (SEM) imaging of bacteria captured by van-PDA-MNPs}

Bacteria enriched with van-PDA-MNPs were washed twice with PBS and the MNPs were separated on a magnetic separation rack. Fixation of the bacteria-MNP complexes was done in $2 \%$ glutaraldehyde solution at RT for $1 \mathrm{~h}[36,37]$. Bacteria-MNP complexes were washed three times with $1 \mathrm{~mL}$ PBS and incubated in $1 \%$ osmium tetroxide for $1 \mathrm{~h}$ at $4^{\circ} \mathrm{C}$ in the dark. Finally, after washing three times with PBS, gradual dehydration of the bacteria-MNP complexes was done in ethanol (30-100\%) for 30 min each. Ten microliters of the bacteria-MNP complexes were dropped onto a 200-mesh copper grid (CF200-CU-50, Electron Microscopy Sciences) and dried at RT for $2 \mathrm{~h}$. SEM observations were obtained by using JSM7500F SEM (JEOL Ltd.) with an accelerating voltage of $5 \mathrm{kV}$. 


\section{Preconcentration in PBS and blood containing a single bacterial strain}

$1 \mathrm{~mL}$ of either PBS or blood containing $10^{4}$ a single bacterial strain (S. aureus, MRSA and B. cereus) $\mathrm{CFU} / \mathrm{mL}$ were mixed with $200 \mu \mathrm{L}$ of either van-PDA-MNPs or van-SiO ${ }_{2}-\mathrm{MNPs}\left(10^{11}\right.$ particles $\left./ \mathrm{mL}\right)$ and incubated at $37^{\circ} \mathrm{C}$ for $30 \mathrm{~min}$. Bacteria-MNP complexes were then separated by using a magnetic separation rack, and the eluent was collected and inoculated on an agar plate to perform standard colony counting. The colony numbers were used to calculate the number of uncaptured bacterial cells during the preconcentration. The following equation was used to calculate the capture efficiency of the MNPs for each species.

$$
\text { Capturing efficiency }(\%)=\left(\frac{N_{t}-N_{u}}{N_{t}}\right) 100 \%
$$

where $N t$ is the number of total bacteria cells in the sample and $N u$ is the number of uncaptured bacteria cells [38].

The preconcentration fold was calculated as follows [39].

$$
\text { Preconcentration fold }=\text { Capturing efficency } *\left(\frac{\text { Initial volume }}{\text { Preconcentrated volume }}\right)
$$

\section{Preconcentration in blood containing multiple bacterial strains}

First, $2.5 \mathrm{~mL}$ of blood containing three strains (S. aureus, MRSA and B. cereus) at different concentrations $\left(10^{1}-10^{4} \mathrm{CFU} / \mathrm{mL}\right)$ were mixed with $200 \mu \mathrm{L}$ of either van-PDA-MNPs or van-SiO${ }_{2}-\mathrm{MNPs}$ $\left(10^{11}\right.$ particles $\left./ \mathrm{mL}\right)$ and incubated at $37^{\circ} \mathrm{C}$ for $30 \mathrm{~min}$. Bacteria-MNP complexes were separated using a magnetic rack and washed three times with $1 \mathrm{~mL}$ PBS.

\section{DNA extraction}

Bacteria-particle complexes were then suspended in $200 \mu \mathrm{L}$ PBS and DNA extraction was performed by using a commercialized DNA purification kit (MagListo ${ }^{\mathrm{TM}} 5 \mathrm{M}$ Genomic DNA extraction kit, Bioneer, Korea). The purity and yield of the extracted DNA were determined based on the ratio of absorbance at wavelengths of 230,260, and $280 \mathrm{~nm}$ using a spectrophotometer (Nano-200, AllSheng, Hangzhou City, China).

\section{PCR}

Forward (5'-ACACCTGAAACAAAGCATCC-3') and reverse (5'-TAGCCAAGCCTTGACGAACT-3') primers were used to amplify $207 \mathrm{bp}$ of nuc gene from purified S. aureus DNA [40]. Purified MRSA DNA was amplified by using the 135-bp mecA gene, forward (5'-AACCACCCAATTTGTCTGCC-3') and reverse (5'TGATGGTATGCAACAAGTCGTAAA-3') primers [41]. Forward (5'-GCCCTGGTATGTATATTGGATCTAC-3') 
and reverse (5'-GGTCATAATAACTTCTACAGCAGGA-3') primers were used to amplify $220 \mathrm{bp}$ of gyrB gene from purified $B$. cereus DNA [42]. MJ MINI thermocycler (Bio-RAD, Hercules, CA, USA) was used to perform PCR. PCR products were separated on a $2 \%$ TAE agarose gel at $100 \mathrm{~V}$ for $30 \mathrm{~min}$.

\section{qPCR}

The same primers were used for both PCR and qPCR. StepOne ${ }^{T M}$ real-time PCR system (Applied Biosystems, Foster City, CA, USA) was used to perform qPCR.

\section{Statistical data analysis}

The data shown are based on the mean \pm standard deviation of three independently performed experiments. T-test was used to compare the data obtained at different conditions. Data with a p-value less than 0.05 were considered significant. $\left({ }^{\star} P<0.05\right.$, ${ }^{\star *} P<0.01$, $\left.{ }^{\star \star *} P<0.001\right)$.

\section{Abbreviations}

Ab: Antibody. Abs: Absorbance. APTES: (3-Aminopropyl)triethoxysilane. ATCC: American Type Culture Collection. B. cereus. Bacillus cereus. CCARM: Culture collection of antimicrobial-resistant microbes. CFU: Colony forming unit. EDS: Energy disruptive spectroscopy. $\mathrm{Fe}_{3} \mathrm{O}_{4}$ : Iron oxide. IMS: Immunomagnetic separation. LB: Luria-Bertani. LOD: Limit of detection. $\mathrm{mL}$ : Millilitre. MNPs: Magnetic nanoparticles. MRSA: Methicillin-resistant Staphylococcus aureus. OD: Optical density. Os04: Osmium tetroxide. PBS: Phosphate-buffered saline. PCR: Polymerase chain reaction. PDA: Polydopamine. qPCR: Quantitative PCR. S. aureus. Staphylococcus aureus. SEM: Scanning electron microscopy. $\mathrm{SiO}_{2}$ : Silicon dioxide. TEM: Transmission electron microscopy. TEOS: tetraethoxysilane. Van: Vancomycin. XPS: X-ray photoelectron spectroscopy.

\section{Declarations}

\section{Ethics approval and consent to participate}

Not applicable.

\section{Consent for publication}

Not applicable.

\section{Availability of data and materials}

Data sharing is not applicable to this article as no datasets were generated or analysed during the current study.

\section{Competing interests}


The authors have no competing interests to declare.

\section{Funding}

This research was equally supported by the BioNano Health-Guard Research Centre as a Global Frontier Project (H-guard NRF-2018M3A6B2057299) funded by the Ministry of Science, Information and Technology (MSIT) of Korea and by a grant (HI20C0629) from the Korea Health Technology R\&D Project through the Korea Health Industry Development Institute (KHIDI), funded by the Ministry of Health \& Welfare of Korea.

\section{Authors' contributions}

ATA, TW, JL and SP planned the project, ATA, TW and DL performed the experiments, ATA, TW, JL and SP analysed the data, ATA and SP wrote the manuscript, GC, LPL and SP supervised the project. All authors read and approved the final manuscript.

\section{Acknowledgments}

We would like to thank Professor Doosung Lee for allowing us to use Zetasizer (Nano ZS).

\section{References}

1. J.-L. Vincent, S.M. Opal, J.C. Marshall, K.J. Tracey. Sepsis definitions: time for change. Lancet 2013; 381: 774-778.

2. K.E. Rudd, S.C. Johnson, K.M. Agesa, K.A. Shackelford, D. Tsoi, D.R. Kievlan, D.V. Colombara, K.S. Ikuta, N. Kissoon, S. Finfer. Global, regional, and national sepsis incidence and mortality, 1990-2017: analysis for the Global Burden of Disease Study. Lancet 2020; 395: 200-211.

3. M. Bauer, K. Reinhart. Molecular diagnostics of sepsis-Where are we today? Int. J. Med. Microbiol. Suppl. 2010; 300: 411-413.

4. H.W. Hou, R.P. Bhattacharyya, D.T. Hung, J. Han. Direct detection and drug-resistance profiling of bacteremias using inertial microfluidics. Lab Chip 2015; 15: 2297-2307.

5. T. Oeschger, D. McCloskey, V. Kopparthy, A. Singh, D. Erickson. Point of care technologies for sepsis diagnosis and treatment. Lab Chip 2019; 19: 728-737.

6. W.A. Al-Soud, P. Rådström. Purification and characterization of PCR-inhibitory components in blood cells. J. Clin. Microbiol. 2001; 39: 485-493.

7. O. Opota, K. Jaton, G. Greub. Microbial diagnosis of bloodstream infection: towards molecular diagnosis directly from blood. Clin. Microbiol. Infect. 2015; 21: 323-331.

8. P. Zhang, A.M. Kaushik, K.E. Mach, K. Hsieh, J.C. Liao, T.-H. Wang. Facile syringe filter-enabled bacteria separation, enrichment, and buffer exchange for clinical isolation-free digital detection and characterization of bacterial pathogens in urine. Analyst 2021; 146: 2475-2483. 
9. H. Fukushima, K. Katsube, Y. Hata, R. Kishi, S. Fujiwara. Rapid separation and concentration of foodborne pathogens in food samples prior to quantification by viable-cell counting and real-time PCR. Appl. Environ. Microbiol. 2007; 73: 92-100.

10. W. Lee, D. Kwon, W. Choi, G.Y. Jung, A.K. Au, A. Folch, S. Jeon. 3D-printed microfluidic device for the detection of pathogenic bacteria using size-based separation in helical channel with trapezoid crosssection. Sci. Rep. 2015; 5: 1-7.

11. Y. Mao, X. Huang, S. Xiong, H. Xu, Z.P. Aguilar, Y. Xiong. Large-volume immunomagnetic separation combined with multiplex PCR assay for simultaneous detection of Listeria monocytogenes and Listeria ivanovii in lettuce. Food Control 2016; 59: 601-608.

12. J. Li, Q. Liu, Y. Wan, X. Wu, Y. Yang, R. Zhao, E. Chen, X. Cheng, M. Du. Rapid detection of trace Salmonella in milk and chicken by immunomagnetic separation in combination with a chemiluminescence microparticle immunoassay. Anal. Bioanal. Chem. 2019; 411: 6067-6080.

13. W.-f. Tong, X.-I. Liu, F. Pan, Z.-q. Wu, W.-w. Jiang. Protein adsorption and cell adhesion on RGDfunctionalized silicon substrate surfaces. Chinese J. Polym. Sci. 2013; 31: 495-502.

14. I.I. Slowing, C.W. Wu, J.L. Vivero-Escoto, V.S.Y. Lin. Mesoporous silica nanoparticles for reducing hemolytic activity towards mammalian red blood cells. Small 2009; 5: 57-62.

15. S. Yang, R.E. Rothman. PCR-based diagnostics for infectious diseases: uses, limitations, and future applications in acute-care settings. Lancet Infect. Dis. 2004; 4: 337-348.

16. W. Ye, Q. Shi, J. Hou, J. Gao, C. Li, J. Jin, H. Shi, J. Yin. Fabricating bio-inspired micro/nano-particles by polydopamine coating and surface interactions with blood platelets. Appl. Surf. Sci. 2015; 351: 236-242.

17. Z. Shi, L. Jin, C. He, Y. Li, C. Jiang, H. Wang, J. Zhang, J. Wang, W. Zhao, C. Zhao. Hemocompatible magnetic particles with broad-spectrum bacteria capture capability for blood purification. J. Colloid Interface Sci. 2020; 576: 1-9.

18. J.H. Ryu, P.B. Messersmith, H. Lee. Polydopamine surface chemistry: a decade of discovery. ACS Appl. Mater. Interfaces 2018; 10: 7523-7540.

19. A. Postma, Y. Yan, Y. Wang, A.N. Zelikin, E. Tjipto, F. Caruso. Self-polymerization of dopamine as a versatile and robust technique to prepare polymer capsules. Chem. Mater. 2009; 21: 3042-3044.

20. Q. Wei, B. Li, N. Yi, B. Su, Z. Yin, F. Zhang, J. Li, C. Zhao. Improving the blood compatibility of material surfaces via biomolecule-immobilized mussel-inspired coatings. J. Biomed. Mater. Res. A 2011; 96 : $38-45$.

21. B. Yu, D.A. Wang, Q. Ye, F. Zhou, W. Liu. Robust polydopamine nano/microcapsules and their loading and release behavior. Chem. Commun. 2009; 28: 6789-6791.

22. M. Zandieh, J. Liu. Spherical Nucleic Acid Mediated Functionalization of Polydopamine-Coated Nanoparticles for Selective DNA Extraction and Detection. Bioconjug. Chem. 2021; 32: 801-809.

23. X. Feng, X. Meng, F. Xiao, Z.P. Aguilar, H. Xu. Vancomycin-dendrimer based multivalent magnetic separation nanoplatforms combined with multiplex quantitative PCR assay for detecting pathogenic bacteria in human blood. Talanta 2021; 225: 121953. 
24. M.M. Hassan, A. Ranzoni, M.A. Cooper. A nanoparticle-based method for culture-free bacterial DNA enrichment from whole blood. Biosens. Bioelectron. 2018; 99: 150-155.

25. M.M. Hassan, A. Ranzoni, W. Phetsang, M.A. Blaskovich, M.A. Cooper. Surface ligand density of antibiotic-nanoparticle conjugates enhances target avidity and membrane permeabilization of vancomycin-resistant bacteria. Bioconjug. Chem. 2017; 28: 353-361.

26. R. Ślusarz, M. Szulc, J. Madaj. Molecular modeling of Gram-positive bacteria peptidoglycan layer, selected glycopeptide antibiotics and vancomycin derivatives modified with sugar moieties. Carbohydr. Res. 2014; 389: 154-164.

27. K. Patel, R. Kumar. Vancomycin Grafted Polydopamine Coated Silver Nanoparticles for Enhanced Antibacterial Action Against Vancomycin-Resistant Bacteria E. Faecalis. ChemistrySelect 2020; 5 : 4701-4707.

28. X. Pan, S. Cheng, T. Su, G. Zuo, C. Zhang, L. Wu, Y. Jiao, W. Dong. Poly (2-hydroxypropylene imines) functionalized magnetic polydopamine nanoparticles for high-efficiency DNA isolation. Appl. Surf. Sci. 2019; 498: 143888.

29. G.M. Sheldrick, P.G. Jones, O. Kennard, D.H. Williams, G.A. Smith. Structure of vancomycin and its complex with acetyl-D-alanyl-D-alanine. Nature 1978; 271: 223-225.

30. C. Wang, B. Gu, Q. Liu, Y. Pang, R. Xiao, S. Wang. Combined use of vancomycin-modified Ag-coated magnetic nanoparticles and secondary enhanced nanoparticles for rapid surface-enhanced Raman scattering detection of bacteria. Int. J. Nanomedicine 2018; 13: 1159.

31. N. Zhao, S. Liu, J. Xing, Z. Pi, F. Song, Z. Liu. Trace determination and characterization of ginsenosides in rat plasma through magnetic dispersive solid-phase extraction based on core-shell polydopamine-coated magnetic nanoparticles. J. Pharm. Anal. 2020; 10: 86-95.

32. G. Yang, X. Meng, Y. Wang, M. Yan, Z.P. Aguilar, H. Xu. 2-Step lectin-magnetic separation (LMS) strategy combined with AuNPs-based colorimetric system for S. aureus detection in blood. Sens. Actuators B Chem. 2019; 279: 87-94.

33. S. Xuan, Y.-X.J. Wang, J.C. Yu, K. Cham-Fai Leung. Tuning the grain size and particle size of superparamagnetic Fe304 microparticles. Chem. Mater. 2009; 21: 5079-5087.

34. P.Y. Furlan, A.Y. Furlan, K. Kisslinger, M.E. Melcer, D.W. Shinn, J.B. Warren. Water as the Solvent in the Stober Process for Forming Ultrafine Silica Shells on Magnetite Nanoparticles. ACS Sustain. Chem. Eng. 2019; 7: 15578-15584.

35. M. Martín, P. Salazar, R. Villalonga, S. Campuzano, J.M. Pingarrón, J.L. González-Mora. Preparation of core-shell Fe304@polydopamine magnetic nanoparticles for biosensor construction. J. Mater. Chem. B 2014; 2: 739-746.

36. D. Martínez-Matamoros, S. Castro-García, M. Balado, A. Matamoros-Veloza, M.A. Camargo-Valero, O. Cespedes, J. Rodríguez, M.L. Lemos, C. Jiménez. Preparation of functionalized magnetic nanoparticles conjugated with feroxamine and their evaluation for pathogen detection. RSC Adv. 2019; 9: 13533-13542. 
37. M. Olivi, E. Zanni, G. De Bellis, C. Talora, M.S. Sarto, C. Palleschi, E. Flahaut, M. Monthioux, S. Rapino, D. Uccelletti. Inhibition of microbial growth by carbon nanotube networks. Nanoscale 2013; 5: 90239029.

38. C. Park, J. Lee, Y. Kim, J. Kim, J. Lee, S. Park. 3D-printed microfluidic magnetic preconcentrator for the detection of bacterial pathogen using an ATP luminometer and antibody-conjugated magnetic nanoparticles. J. Microbiol. Methods 2017; 132: 128-133.

39. Y. Kim, A.T. Abafogi, B.M. Tran, J. Kim, J. Lee, Z. Chen, P.K. Bae, K. Park, Y.-B. Shin, D. van Noort. Integrated microfluidic preconcentration and nucleic amplification system for detection of influenza A virus H1N1 in saliva. Micromachines 2020; 11: 203-213.

40. Y. Kim, J. Lee, S. Park. A 3D-printed millifluidic platform enabling bacterial preconcentration and DNA purification for molecular detection of pathogens in blood. Micromachines 2018; 9: 472-483.

41. L.E. O'Donnell, K. Smith, C. Williams, C.J. Nile, D.F. Lappin, D. Bradshaw, M. Lambert, D.P. Robertson, J. Bagg, V. Hannah. Dentures are a reservoir for respiratory pathogens. J. Prosthodont. 2016; 25: 99104.

42. M. Dzieciol, M. Fricker, M. Wagner, I. Hein, M. Ehling-Schulz. A novel diagnostic real-time PCR assay for quantification and differentiation of emetic and non-emetic Bacillus cereus. Food Control 2013; 32: $176-185$.

\section{Tables}

Table 1. Elemental composition of the dried MNPs and their relative atomic concentration was studied by exciting the MNPs to mono-energetic Al ka x-rays and measuring the energy of photoelectrons emitted by electron energy analyser (ESCALAB250 XPS analyser).

\begin{tabular}{|llllll|}
\hline Sample & \multicolumn{5}{|c|}{ Relative atomic mass (\%) } \\
\cline { 2 - 6 } & $\mathrm{Fe}$ & $\mathrm{O}$ & $\mathrm{C}$ & $\mathrm{N}$ & $\mathrm{Cl}$ \\
\hline MNPs & 24.8 & 48.4 & 26.8 & - & - \\
\hline PDA-MNPs & - & 24.0 & 69.5 & 6.5 & - \\
\hline Van-PDA-MNPs & - & 23.3 & 65 & 10.2 & 1.5 \\
\hline
\end{tabular}

Table 2. Yield and purity of genomic DNA extracted from $S$. aureus at various concentrations (10-104 $\mathrm{CFU} / \mathrm{mL}$ ) in the blood through preconcentration with van-SiO ${ }_{2}-\mathrm{MNPs}$ and van-PDA-MNPs. After preconcentration, bacterial DNA was extracted by using a kit (MagListoÔ 5M Genomic DNA extraction kit). DNA purity and concentration were determined by the ratio of absorbance (abs.) at 230, 260 and 280 nm by using a spectrophotometer (Nano-200). 


\begin{tabular}{|lllllll|}
\hline CFU/mL & \multicolumn{3}{l}{ Van-SiO ${ }_{2}$-MNPs } & \multicolumn{3}{l|}{ Van-PDA-MNPs } \\
\cline { 2 - 7 } & $\begin{array}{l}\text { Abs. } \\
(260 / 230)^{1}\end{array}$ & $\begin{array}{l}\text { Abs. } \\
(260 / 280)^{2}\end{array}$ & $\begin{array}{l}\text { DNA conc. } \\
(\mathrm{ng} / \mu \mathrm{L})\end{array}$ & $\begin{array}{l}\text { Abs. } \\
(260 / 230)\end{array}$ & $\begin{array}{l}\text { Abs. } \\
(260 / 280)\end{array}$ & $\begin{array}{l}\text { DNA conc. } \\
(\mathrm{ng} / \mu \mathrm{L})\end{array}$ \\
10 & $1.9 \pm 0.3$ & $1.6 \pm 0.2$ & $17.1 \pm 1.7$ & $2.4 \pm 0.1$ & $1.9 \pm 0.1$ & $32.8 \pm 0.6$ \\
$10^{2}$ & $1.9 \pm 0.1$ & $1.5 \pm 0.7$ & $6.4 \pm 0.7$ & $2.2 \pm 0$ & $1.8 \pm 0$ & $37.4 \pm 0.3$ \\
$10^{3}$ & $1.8 \pm 0$ & $1.3 \pm 0$ & $10.9 \pm 0.6$ & $2.2 \pm 0$ & $1.6 \pm 0.1$ & $44.2 \pm 1.2$ \\
$10^{4}$ & $2.1 \pm 0.3$ & $1.7 \pm 0.3$ & $18.6 \pm 0.3$ & $2.2 \pm 0.1$ & $1.8 \pm 0.1$ & $64.4 \pm 0.6$ \\
\hline
\end{tabular}

${ }^{1}$ The absorbance ratio at 260 and $230 \mathrm{~nm}$ is used to assess the presence of contaminants such as phenol, that absorbs strongly at or near $230 \mathrm{~nm}$.

${ }^{2}$ The absorbance ratio at 260 and $280 \mathrm{~nm}$ is used to assess the presence of proteins and other contaminants that absorb strongly at or near $280 \mathrm{~nm}$.

\section{Figures}

\section{Figure 1}

Schematics illustrating bacterial preconcentration without non-specific aggregation in the blood using vancomycin-conjugated polydopamine-coated magnetic nanoparticles (van-PDA-MNPs) instead of vancomycin-conjugated silica-coated magnetic nanoparticles (van-SiO ${ }_{2}-\mathrm{MNPs}$ ) for sepsis molecular diagnostics.

\section{Figure 2}

Schematic representing the synthesis of PDA-MNPs and van-PDA-MNPs. Freshly prepared MNPs form larger MNPs through dopamine coating. Van was grafted to PDA-MNPs through the reaction of primary amino groups of van to phenyl rings of PDA.

\section{Figure 3}

Characterization of iron oxide MNPs, PDA-MNPs and van-PDA-MNPs. (a) Images of each type of MNP on a 300-mesh copper grid obtained by TEM (JEM-2100F) (JEOL Ltd.). Element composition in (b) MNPs, (c) 
PDA-MNPs and (d) van-PDA-MNPs using XPS. Each type of MNP was placed on a glass slide and their

elemental composition was studied by exciting the MNPs to a mono-energetic Al ka x-rays and measuring the energy of photoelectrons emitted by electron energy analyser (ESCALAB250 XPS analyser). (e) Zeta potential of each type of MNP measured using a Zetasizer Nano ZS (Malvern Instruments). (f) Elemental mapping of van-PDA-MNPs obtained by TEM with EDS. Student's $t$-test, $* \star *: P<0.001$. **: $P<0.01$.*: $P<$ 0.05. $n=3$.

\section{Figure 4}

Dispersion of van-SiO 2 -MNPs and van-PDA-MNPs in PBS (a) and blood (b). Particle size distribution of the MNPs were analysed using Zetasizer. Two hundred microliters of each type of MNP were added to PBS or blood and incubated at $37^{\circ} \mathrm{C}$ for $30 \mathrm{~min}$. MNPs were then separated using a permanent magnet and washed with PBS and the size distribution of van-SiO ${ }_{2}-M N P s$ (c) and van-PDA-MNPs (d) was analysed.

\section{Figure 5}

Binding of van-PDA-MNPs with bacteria. (a) SEM images of bacteria captured by van-PDA-MNPs. The capturing efficiency of van-PDA-MNPs and van-SiO ${ }_{2}$-MNPs for different species of bacteria in PBS (b) and blood (c) was analysed by using the colony counting method. The capture efficiency was calculated based on the initial number of bacteria in the sample and the number of uncaptured bacteria cells in the eluent sample. Preconcentration fold in PBS (d) and blood (e). The preconcentration fold was estimated based on the capture efficiency and the ratio of initial and final sample volume. Student's $t$-test, $* * *: P<$ 0.001. **: $P<0.01 . *: P<0.05 . \mathrm{n}=3$.

\section{Figure 6}

Improvement in the sensitivity of qPCR (a) and PCR with gel electrophoresis (b-d) for the detection of $S$. aureus in spiked blood samples through the preconcentration of the microorganism using van-PDAMNPs. Ct value plotted against $S$. aureus at different concentrations $\left(10^{1}-10^{4} \mathrm{CFU} / \mathrm{mL}\right)$ in spiked blood samples with and without the preconcentration by van- $\mathrm{SiO}_{2}-\mathrm{MNPs}$ or van-PDA-MNPs. (b-d) Gel electrophoresis images of the amplified DNA (207 bp) of the target gene (nuc) by PCR with (c, d) and without (b) the preconcentration. 
qPCR (a-c) and PCR with gel electrophoresis (d-f) for the detection of Gram-positive bacteria (S. aureus (a, d), MRSA (b, e) and B. cereus $(\mathbf{c}, \mathbf{f}))$ in the blood through the simultaneous preconcentration of the microorganisms using van-PDA-MNPs. Details of each primer set and its target gene are found in the Materials and Method section.

\section{Supplementary Files}

This is a list of supplementary files associated with this preprint. Click to download.

- AdditionalfileJNBAbdurhamanFeb26.docx 